This is a pre-copyedited, author-produced PDF of an article accepted for publication in Social History of Medicine following peer review. The definitive publisher-authenticated version 'gentle Purges corrected with hot Spices, whether they work or not, do vehemently provoke Venery': Menstrual Provocation and Procreation in Early Modern England' Social History of Medicine 25/1 (February 2012) is available online at http://shm.oxfordjournals.org/content/25/1/2.full?sid=49445019-642b-4764-8644$7 e 432368 c f 39$

\title{
'gentle Purges corrected with hot Spices, whether they work or not, do vehemently provoke Venery': Menstrual Provocation and Procreation in Early Modern England.
}

Present in early modern medical literature of all kinds were compound remedies, composed of several ingredients, and simples, individual substances, designed to remove obstructions and provoke menstrual flow. Many historians, such as Angus Mclaren, Edward Shorter, John M. Riddle and Laura Gowing, have identified herbs, and other emmenagogues such as iron filings, as a clandestine form of abortifacient, designed to remove an untimely or simply unwanted pregnancy. ${ }^{1}$ In 1989 Roy Porter argued that during the long eighteenth century many remedies which 'promised to remove “female obstructions", and to procure, or renew menstruation' were actually substances that could be used to induce abortion. ${ }^{2}$ Similarly Tim Hitchcock, in English Sexualities, explained that birth control in eighteenth-century England included a variety of practices. ${ }^{3}$ Of these, he wrote that,

\footnotetext{
${ }^{1}$ For examples see, Mclaren 1984, pp.102-106; Mclaren 1981 p. 231; Shorter 1984, pp.1818; Riddle 1991, p.11 - 23; Gowing 1997, p. 97.

${ }^{2}$ Porter 1989, p. 148.

${ }^{3}$ Hitchcock 1997, p. 52. Stone 1977, pp. 266-7.
} 


\begin{abstract}
Abortion of one sort or another was certainly the form of birth control spoken of most frequently. Throughout the early-modern period recipes for medicines to 'bring down the flowers', or to regulate menstruation, were a common component of any herbal or recipe book, and could certainly be obtained from the local apothecary. ${ }^{4}$
\end{abstract}

Once again Hitchcock left little room for the discussion of these substances as a measure to increase fertility. More recently Laura Gowing in Common Bodies (2003) and Sarah Toulalan in Imagining Sex (2007) have both stated that 'women's knowledge of the female body and its reproductive capacities included awareness (and use) of herbs and potions to prevent pregnancy, as well as techniques for "unblocking" the courses, or menstrual period. ${ }^{5}$ These works do not completely disregard the ability of emmenagogues to promote conception; but they more frequently portray them as a means of procuring abortion. The acknowledgement of these substances as a part of sexual health practices associated with fertility remains a neglected aspect of the historiography.

This may in part reflect the tendency for feminist historians, and historians of women's history, to investigate abortion in early modern England as a means of demonstrating women's agency and control over their own bodies. For example In Blood, Bodies and Family Patricia Crawford stated that 'as a method for preventing birth, abortion was successful. It was not a crime

\footnotetext{
${ }^{4}$ Stone 1977 , p.52.

${ }^{5}$ Quote from; Toulalan 2007, p.74; Gowing 2003, pp. 47, 120.
} 
before the quickening of the child, and was under female control. ${ }^{6}$ Additionally she noted that women's agency in this case was not necessarily subordinate to male medical authority with women able to use physicians to provoke an abortion under the guise of restoring menstruation. ${ }^{7}$ Similarly Gowing mentions that the knowledge associated with inducing abortions could be guarded by early modern women as a part of female sexual knowledge. ${ }^{8}$ The difficulty in assessing the true extent of abortion practices in early modern England has allowed for this interpretation which reads between the lines. This combined with the desire to discover histories specifically about women, their bodies and their actions suggests why this interpretation of emmenagogues has become popular.

The absence of a more nuanced approach to interpreting these substances, especially in studies of early modern England, is particularly surprising as Etienne Van de Walle has emphatically argued that women in many geographical and historical settings have sought to manipulate their menstrual flow to promote fecundity. ${ }^{9}$ In 'Flowers and Fruits', which traces Greek and Roman medicine through to the early modern period, Van de Walle examined the emmenagogues listed in herbals and demonstrated their role in tempering the matrix and promoting conception, as well as attempting to outline the level of practical application associated with these drugs. ${ }^{10}$ Moreover, Van de Walle and Renne believe that those such as Riddle and Mclaren may have overstated the evidence when they accepted that many emmenagogues were

\footnotetext{
${ }^{6}$ Crawford 2004, p. 71.

${ }^{7}$ Crawford 2004, p. 34.

${ }^{8}$ Gowing 2003, p. 47.

${ }^{9}$ Van de Walle and Renne 2001, pp. ix, $x$.

${ }^{10}$ Van de Walle 1997, pp. 192-3, 195-201.
} 
simply used as abortifacients. ${ }^{11}$ Van de Walle's suggestions have encouraged new interpretations of these remedies. In her detailed examination of the original Hippocratic corpus of gynaecological recipes Laurence Totelin argued that ingredients identified as abortive or expelling drugs could also be used in compositions that furthered sexual health. ${ }^{12}$ She has concluded that in the Hippocratic recipes helping conception was a very similar process to purging and regulating the menstrual cycle. ${ }^{13}$ In this situation she has argued that it is important not to interpret all Hippocratic gynaecological purges as abortions. $^{14}$

Many early modern recipes were founded upon the fundamental teachings of Hippocratic and Galenic medicine. Thus, it is apparent that the medical framework of the early modern period would not have automatically categorised these substances as wholly negative. Accordingly, Gowing has suggested that a more nuanced interpretation of abortive and an emmangogic drugs is necessary for this period. Following her revelation that women used these substances for abortive purposes, concluded that,

while these phrases [, such as bringing down the terms,] can be read as euphemisms for early abortion, in the context of early modern prescriptions of pregnancy, they make sense on their own terms: what we recognise as early pregnancy could be

\footnotetext{
${ }^{11}$ Van de Walle and Renne 2001, p. xiv.

12 Totelin 2009, p. 214.

13 Totelin 2009, p. 216.

14 Totelin 2009, p. 217.
} 
perceived, then, as an obstruction in the menstrual flow which might, or might not, eventually lead to a quick child. ${ }^{15}$

Cathy McClive has also conducted extensive research into the attitudes of medical practitioners towards menstruation in early modern France. She has demonstrated that physicians and medical writers were concerned about menstrual regularity: physicians often attempted to rectify and restore vicarious menstrual bleeding, superfluous blood that could not escape through the uterus and so left the body through the anus, nose or ears, to ensure women's fertile potential. $^{16}$

The following examination aims to build upon this foundation and contribute to this debate by addressing in greater detail the role of specifically early modern emmenagogues in promoting fertility. One of the principal way in which this role can be assessed is by examining the evident similarities between aphrodisiacs and emmenagogues. A striking parallel can be identified between simples which functioned to enhance fertility and those which promoted menstruation: both sets of herbs, spices and animal substances were predominantly classified as hot and dry by herbals. Similarly herbals often listed foods which served to encourage both of these results. In examining compound recipes, numerous aphrodisiacs can often be identified in remedies designed to purge the womb and ensure proper menstruation. Therefore, it would seem plausible to argue that the close proximity of these two types of simple and the prominent place of provokers of lust in these

\footnotetext{
${ }^{15}$ Gowing 2003, p. 120.

${ }^{16}$ McClive in Shail and Howie (eds) 2005, p. 86.
} 
recipes indicates that emmenagogues served not only as a form of abortion but as a means to improve the fertility of the generative organs. This should in no way replace the interpretation of these medicines as abortifacients but should be considered concurrently to highlight the versatile, and sometimes contradictory, nature of early modern sexual health recipes.

\section{Context}

This article particularly addresses the understanding of fertility between 1550 and 1780. Tim Hitchcock has asserted that England between 1650 and 1750 was characterised by stagnant population growth and reduced fertility. ${ }^{17}$ This started to change around 1701 when the age of marriage began to fall. ${ }^{18}$ It was not, however, until after 1750 that an increase in fertility became apparent. ${ }^{19}$ Demographers have also noted that the early modern period was a time when early infant and childhood mortality rates were relatively high. ${ }^{20}$ Thus, the production of offspring during the early modern period was particularly precarious. The difficulties in conceiving were noted by some in society. Robin Ganev has stressed that 'Most eighteenth-century writers expressed fears that the English were not producing enough healthy children'. ${ }^{21}$ Ganev suggested that within this context the vigorous and virile sexuality of the agricultural, rural, classes was perceived in stark contrast to the 'pervasive stereotype ... of the impotent nobility, whose sexuality was

\footnotetext{
17 Hitchcock 1997, p. 25.

${ }^{18}$ Hitchcock 1997, p.26.

19 lbid, p.26.

20 Galley 1994, 29-57; Razzell and Spence 2007.

21 Ganev 2007, 46.
} 
debilitated by urban luxury. ${ }^{22}$ These stereotypes certainly existed throughout the period in the medical literature. William Buchan wrote in 1772 that 'It is very certain that high living vitiates the humours, and prevents fecundity. ${ }^{23} \mathrm{He}$ further asserted, in line with Ganev's understanding of eighteenth-century discourse on fertility, that 'we seldom find a barren woman among the labouring poor, while nothing is more common amongst the rich and affluent. ${ }^{24}$ Additionally, Mendelson and Crawford, Porter and Hall, and Gowing have all noted the centrality of concerns about fertility in early modern society. ${ }^{25}$ The poor fertility rates demonstrated by demographers for this period makes it particularly relevant for the study of emmenagogues and their associated functions as it will perhaps elucidate the ways in which the understanding and use of these substances was inherently shaped by the cultural, social and demographic situations of a particular historical period.

The understanding, categorisation and use of emmenagogues, and sexual provocatives, demonstrated in this article is predominantly gleaned from vernacular printed medical works, written by physicians and medical writers. Printed works flourished during the early modern period and in particular medical and midwifery texts formed a popular genre. Laura Gowing has explained that ' $A$ whole genre of medical texts, from cheap palm sized books to costly folio treatises, was dedicated to expounding the greatest mystery of all: 'generation', or reproduction. ${ }^{26}$ She further asserted that 'The years of the

\footnotetext{
${ }^{22}$ Ganev 2007, 42.

${ }^{23}$ Buchan 1772, p.667.

24 Ibid.

${ }_{25}$ Mendelson and Crawford 1998, p. 150; Porter and Hall 1995, p. 46; Gowing 2003, p. 114.

${ }^{26}$ Gowing 2003, p.17.
} 
civil wars and commonwealth, when print censorship was suspended and radicals argued against medical elitism, saw a rapid increase in the publication' of this form of self-help literature. ${ }^{27}$ This potentially had much to do with the growth of literacy and consumer culture which created favourable conditions for the consumption of these works. ${ }^{28}$ Furthermore, the ways in which printed works were read and utilised means that they can provide evidence about medical practice. Stephen Dobranski has argued that during the seventeenth century readers had to make texts meaningful and thus texts were often appropriated for their own ends. ${ }^{29}$ In the case of medical works and herbals, and perhaps to some extent popular literature, this would have resulted in readers recording potentially useful remedies and using the medical knowledge acquired to assist them in obtaining adequate medical care. This humanist tradition was reflected in the practice of keeping a commonplace book where useful information from reading, and discussions with friends, was noted down and recorded to create a new volume of knowledge specific to individual needs. It was out of this practice that the tradition of keeping a medical and culinary receipt book developed. Moreover, Patrick Wallis, Elaine Leong and Deborah Harkeness have all noted the interactions between printed medical works and popular medical practices. ${ }^{30}$ This makes these works a pertinent source for the study of elite and popular medical knowledge as well as medical practice.

\footnotetext{
${ }^{27}$ lbid.

${ }^{28}$ Porter and Hall 1995, p. 35.

29 Dobranski 2005, p. 22.

${ }^{30}$ Wallis in Hill Curth (ed.) 2006, p. 16; Leong 2008, 145- 68; Harkness in Evans and Marr (eds) 2006, p. 175.
} 
Many of the medical texts offered for sale during this period were vernacular translations of European texts. The origins of these texts, however, did not make them irrelevant to English readers. Furdell has noted that few original works of anatomy were produced in England, because dissection interfered

with a body's readiness for the final judgement. ${ }^{31}$ It was thus important for English medical practitioners to have access to the works of continental anatomists. The publication of medical works in Latin, the universal language of medicine, allowed them to form a culture of European medicine. England was not isolated, in terms of medical developments and understanding; it was a part of the broader culture of medical enquiry, innovation and learning that was being practiced in universities across Europe. Finally the translation of these works into the vernacular increased their accessibility and their readership. Thus, foreign works were an integral part of British medical knowledge as medical writers, practitioners and consumers all participated in a shared European medical culture. As has been noted above, McClive has demonstrated that French physicians were concerned with the regularity of menstruation and it will be shown here that this concern was also wide-spread in English language texts, It is therefore plausible that English concerns about the reproductive body closely mirrored those seen on the continent.

\section{The humoral body and sexual health}

Early modern medicine was based fundamentally upon the humoral model of the body developed by Hippocrates and Galen. The body was composed of

\footnotetext{
${ }^{31}$ Furdell 2002, p. 50.
} 
four humours: black bile, yellow bile, blood and phlegm, which had to be kept in balance to prevent ill health and disease. In terms of sexual health, the womb had to be maintained and steps had to be taken to ensure that the humoral balance of the womb was favourable to the conditions needed for procreation. The womb could not be too moist, cold, dry or hot: an excess of any of these qualities would potentially damage the ability of the woman to conceive a child. Most importantly the womb had to be warm as heat encouraged sexual pleasure and the production of potent seed which were vital for generation. This understanding of the generative body and its component parts dictated the types of medication which were recommended to combat infertility and ensure fecundity. Although innovative medical theories arose during the early modern period, notably chemical medicine, much of the understanding of the properties and virtues of medicinal ingredients remained within the humoral framework. Chemical medicines provided potent, concentrated, forms of a substance's virtues but these virtues were still based upon the humoral qualities of the original plant or animal. Moreover, in terms of medical practice, the adoption and incorporation of chemical remedies into popular medicine may have been a slow process. Medical writers wished to promote recipes and remedies which would appeal to their readers and so continued to base their medicines upon the traditional, widely understood, humoral model.

Some of the most common types of medication offered to those attempting to conceive a child were provokers of lust, or aphrodisiacs as they came to be known from the late seventeenth century. These substances could augment 
the generative system in several ways: providing nutrition which aided seed production, imparting sexual prowess through the doctrine of signatures, or filling the body with wind. A key category of provocatives discussed and recommended during this period was hot foods. Within this group were foods which raised the heat of the body or produced a warming sensation when consumed, including meats, animal secretions, herbs and spices. These substances, by heating the body, increased the desire for and the pleasure experienced in intercourse. This combated the devastating effects of frigidity which, through coldness, robbed the body of its ability to experience sexual pleasure and its ability to conceive. Hotter genital members retained the vital heat of the seed and so increased the likelihood of sexual intercourse culminating in the sparking of a conception. Numerous physicians and medical writers across the sixteenth, seventeenth and eighteenth centuries expounded the virtues of these foods. Jakob Rueff recommended in The Expert Midwife (1637) that a cold womb should be rectified by the use of 'things of a hot nature'. ${ }^{32} \mathrm{He}$ implied, earlier in the text, that this would improve the pleasure and desire felt by the female generative organs; as a hot womb experienced 'a love and desire to Venus, [and] a speedy pleasure and delight' in the act of coition. ${ }^{33}$ Thus it is plausible to assume that both Rueff and his audience would have acknowledged that heating the womb with warm foods would stimulate desire. Rueff also related numerous recipes that were to cure those 'hindered very much for want of desire to be acquainted with Venus'

\footnotetext{
${ }^{32}$ Rueff 1637 , p. 50. Originally published in 1554 .

${ }^{33}$ Rueff 1637, p. 54.
} 
which included heating herbs, such as galingale, rocket, pepper, ginger and cinnamon, yet the effects of these recipes were not discussed. ${ }^{34}$

Seventeenth-century authors continued to explain that hot foods were sexually stimulating. Lævinus Lemnius advised that those experiencing sexual dysfunction should amend their diet to change the 'Elementary qualities' of the reproductive organs. ${ }^{35}$ Of most benefit, he suggested, were those 'meat[s] as will make them fruitful for propagation; Amongst such things as stir up Venery, and breed seed for generation, are all meats of good juice, that nourish well, and make the body lively and full of sap, of which faculty are all hot and moist meats. ${ }^{36}$ Lemnius' loose description suggests that a vast number of hot, and moist, foods were considered to be provokers of venery. Similarly, Felix Platter definitively stated that to cure a 'Defect, or Want of Copulation', in addition to the use of other aphrodisiacs, 'we add hot things which may make the blood hotter, by consequence the seed, which will more stimulate or provoke; and by its heat and thinness come sooner and in greater plenty to the Yard. ${ }^{37}$ While these two authors implied that all hot foods could be utilised for this purpose, other authors provided more specific lists of heating aphrodisiacs. Philip Barrough suggested that 'they which be maried, and cannot use the act of generation, because of the sluggish impotencie and weaknesse of their members' should 'use meates that do heate and engender good humours: as is the fleshe of hennes, capons, patrich, feasantes, yong

\footnotetext{
${ }^{34}$ Rueff 1637, pp. 55-61.

${ }^{35}$ Lemnius 1658 , p. 26.

${ }^{36}$ Ibid.

${ }^{37}$ Platter 1662, p. 170.
} 
doves, birdes of mountains, and specially sparrowes, cockes stones and such like. ${ }^{38}$

Although medical authors in the eighteenth century ceased to provide lists of specific heating herbs as a remedy for sexual dysfunction, they did retain the understanding that heat was beneficial to the generative organs. In 1743, Jean Astruc simply commented that barren women who were 'naturally cold and insensible of Pleasure during the venereal Action' should be treated with 'Remedia Aphrodisiaca ... which are met with almost in all medicinal Books and which should be made hot to warm the Patient. ${ }^{39}$ Thus, it is clear that heat continued to have a direct relationship with the stimulation of desire and pleasure. Although it is not necessarily the substances themselves that are considered hot it is apparent that any form of heat was considered beneficial in the treatment of generative dysfunction. Similarly, in 1770, John Ball recommended that the 'most powerful medicines should be taken, which will warm and invigorate the blood and juices. ${ }^{40}$ The compound remedies he proceeded to propose contained cinnamon, saffron, candied nutmeg, candied ginger and eringo; all of which were heating spices used to treat sexual dysfunction. ${ }^{41}$ Consequently it is clear that the humoral model for improving the reproductive and sexual capacity of the generative organs, which predominantly advocated heating the body, persisted into the late eighteenth century.

\footnotetext{
${ }^{38}$ Barrough 1590, p. 182.

${ }^{39}$ Astruc 1743, pp. 344-5.

${ }^{40}$ Ball 1770, p. 73.

${ }^{41}$ Ball 1770, pp. 73-4.
} 
The listing of aphrodisiac foods expressly linked with heat was also prevalent in the herbals of this period. One of the problems with the descriptions provided in herbals is that the plants and other substances were often listed simply as provokers of lust, without an overt explanation of the effects they had upon the generative organs. Nevertheless, it is clear that the humoral framework's emphasis on heat had been transferred into these texts. Many authors related the humoral degree of each plant; stating whether it was hot, cold, dry or moist and to what extent each of these characteristics dominated. The majority of plant roots, flowers and herbs listed as aphrodisiacs in this genre of texts were considered to be hot and dry, or hot and moist. For example, Anthony Askham wrote that savoury was hot and dry in the third degree, and that it 'stirreth him tha[t] useth it to lechery, therfore it is forbyden to use it muche in meates. ${ }^{42}$ The seventeenth-century edition of John Gerard's The Herball or Generall Historie of Plantes listed bastard parsley, wild chervil, saffron, small nettle, the lesser sun flower, Claire, and burdock in the same manner. ${ }^{43}$ In these cases it can be argued that the reader was supposed to understand the intimate connection between heat and sexual stimulation, and so no further explanation was required. The herbal merely provided a reference for people to find a plant that would serve their purpose. Other provokers of lust listed as hot and dry in the second, third or fourth degree included elecampane, eringo, galingale, southernwood, rocket, garden cresses and cloves. ${ }^{44}$ As will be seen, the relationship of emmenagogues to sexual provocatives is crucial in viewing these substances, in a counter-

\footnotetext{
${ }^{42}$ Askham 1550, Sig. jiiv and jiiir.

${ }^{43}$ Gerard 1633, pp. 1023, 1041, 152-4, 207, 707, 751-2, 770,810-1.

${ }^{44}$ Culpeper 1655, pp. 6, 7, 16, 26, 41.
} 
intuitive way, as a part of early modern sexual practices, rather than as nothing more than abortifacient drugs.

\section{Menstruation and Fertility in Early Modern England}

The female generative organs were a mysterious entity in the early modern period. Menstruation and in particular the qualities of menstrual blood were discussed and debated across the period. Medical writers explained that menstrual blood could be either a plethora of innocuous blood released from the body, or a dangerous and toxic excrement which threatened to poison the female body. The role of menstrual blood in the generative process was also disputed and considered across the period. For physicians and medical authors who subscribed to the two seed model, women's menstrual blood provided the nutrition given to the baby during gestation. Conversely for those who followed the one seed model of generation menstrual blood was the women's contribution to the forming fetus; it was shaped and invigorated by the male semen at the point of conception to create the new life. Consequently, whether a nutritious superfluity or the woman's contribution to conception, menstrual blood was a key component in the reproductive process.

Susan Klepp has remarked of eighteenth-century America that medical, and other, sources fail to link emmenagogues to infertility. ${ }^{45}$ However, Joan Cadden has suggested that for medical men in the Middle Ages 'Menstrual

\footnotetext{
${ }^{45}$ Klepp in Van de Walle and Renne (eds) 2001, p. 23.
} 
retention [was] the most prominently featured cause of sterility among women', with John of Gaddesden actually placing it 'first in his list of ten intrinsic causes'. ${ }^{46}$ Similarly during the early modern period general medical texts and midwifery manuals often expressed the concern that an irregular menstrual cycle could prevent a woman from conceiving a child. Mary Fissell has adequately demonstrated that Raynalde's midwifery text of 1545 viewed menstrual blood as a pure nourishing substance that was essential for conception. ${ }^{47}$ Likewise Jakob Rueff stated in 1554 that the state of a woman's menstrual flow affected the health of her entire body. He wrote 'so that her body be of a sound and healthfull constitution, [it] ought naturally to be Purged and cleansed from this superfluous matter every moneth. ${ }^{48} \mathrm{He}$ further lamented that 'every woman deprived of these Flowers, I say, of this purging in her due season by the course of Nature, can neither conceive, nor ingender, being like unto an unfruitful and barren man, destitute and deprived of the same vertue, and faculty of ingendering. ${ }^{49}$ It is clear from Rueff's statement that irregular menstruation was not simply detrimental to fertility but entirely destructive of the womb's ability to bear children. This sentiment was echoed by the Padua professor Alessandro Massaria in $1657 .^{50}$ He wrote of the dangers to a woman's body if her monthly purgation was suppressed, stating that 'if there be a perpetual suppression of the Terms, then it plainly shows such a Woman to be absolutely barren. ${ }^{51}$ Again, Massaria emphasised that the effects of not experiencing proper menstruation were severe: it could

\footnotetext{
${ }^{46}$ Cadden 1993, p. 250.

47 Fissell 2004, pp. 32-33.

${ }^{48}$ Rueff 1637, p. 11.

49 lbid.

50 Information on Massaria, Thorndike 1941, p. 368.

${ }^{51}$ Massaria 1657, p. 20.
} 
mean the total loss of a woman's reproductive capacity. He also explained that this disorder could be intimately linked with the humoral constitution, as Rueff also implied, as the deficiency could be caused by obstructions, excessive fatness or leanness or coldness of the womb which made the woman dull, drowsy, and slowed her pulse. ${ }^{52}$ It might, therefore, be expected that remedies which served to alter the humoral state of the body, such as heating aphrodisiacs, would be employed to readdress the constitutional balance.

Across the period medical writers continued to examine the role of menstruation in the generative process. The understanding reported in these texts shows little deviation or progression and underscores the consistency of the humoral medical model. Indeed, as Helen King has shown, although new theories of menstruation were considered in the seventeenth century, the traditional Galenic view of menstrual blood was retained in British medicine into the eighteenth century. ${ }^{53}$ In the late seventeenth century Jane Sharp addressed her readers' concerns about what hindered conception. As a part of her advice she wrote that 'let such as desire to have children, look to it that their courses come down orderly, and be well coloured, for then there is no fear but such women will be easie to conceive. ${ }^{, 54}$ By explaining the role of menstruation in this way Sharp may have encouraged her readers to provoke the courses themselves. This text explicitly states that the woman must make

\footnotetext{
52 Ibid.

${ }^{53}$ King 2004, p. 72.

${ }^{54}$ Sharp 1671, p. 180.
} 
certain that her 'courses come down orderly', overtly encouraging active measures to reinstate the proper menstrual cycle.

The centrality of proper menstruation to the fertile body was also expounded throughout the eighteenth century. In 1737, Henry Bracken, physician, surgeon, and man-midwife of Lancaster, wrote that a total suppression of the menses barred all pregnancy. ${ }^{55}$ Similarly, the contemporary edition of the Ladies Physical Directory listed a deficiency of the monthly terms as the primary cause of barrenness, explaining that 'then the natural sparkling Briskness of the Blood and Juices is wanting, the lively desirous Faculty is spoiled, neither is the womb fit to receive the spirituous ... Masculine Semen, that Conception might follow. ${ }^{56}$ For these authors a deficiency of the menses was detrimental to the generative ability of the body in terms of supporting coition, sexual pleasure and conception. Moreover, the descriptions provided in their works would have supplied their readers with a context in which the provocation of absent menstruation would have been entirely understood within the framework of treatments for barrenness. The explanations that readers would have been confronted with also emphasised the role of the humoral constitution in the correction of this problem, particularly the dangers of a cold body, and the link to increased sexual desire and pleasure. Thus, it is conceivable that the authors of the texts seen here would have advocated the use of aphrodisiac substances to invigorate the body with heat and pleasure alongside substances that would encourage a natural flow of blood.

\footnotetext{
${ }^{55}$ Bracken 1737, p. 28. Information on Henry Bracken from The Oxford Dictionary of National Biography, http://www.oxforddnb.com, accessed 26.11.09.

${ }^{56}$ Anon. 1739 , p. 48 . In 1770 John Ball also noted that a stopping of the menses was problematic for conception; Ball 1770, p. 70.
} 
Within this framework it is also clear that many women would have viewed remedies to provoke menstruation as falling entirely within the realms of sexual health practice, rather than simply as a way to remove an unwanted pregnancy.

\section{Provoking Menstruation to Ensure Fertility}

As Van de Walle and Renne, briefly mentioned, in addition simply to noting the importance of regular monthly purgation medical writers of the early modern period recommended recipes that could be used to purge the body of this retained blood and revive a natural and timely cycle. These recipes could include substances which 'have a dark reputation as abortifacients'. ${ }^{57}$ While it is clear that these remedies could be easily utilised for the purposes of removing a blockage or an obstruction, in the form of a newly forming fetus, it is also apparent that they were designed to serve a beneficial purpose. As Laurence Totelin has demonstrated in the Hippocratic Corpus 'purges were often conceived as the first step towards conception. ${ }^{58}$ In the sixteenth century Jakob Rueff explained as a part of his 'generall Precepts serving for the curing of the barrenness' that:

let women observe and consider the complexion and state of the Matrix, and let them warily marke their Termes, lest in the time when they issue forth, or when they are cleared from them, they use an inconvenient diet, but rather they use most especially

\footnotetext{
${ }^{57}$ Van de Walle and Renne 2001, p. xxi.

58 Totelin 2009, p. 217.
} 
things which are knowne to have an expulsive vertue and force to expel out of the body: such as are parsley, Stone-parsley, Fennel, the herbe which the Germans call commonly Pimpinella, with the like herbes and roots of the same nature and quality. ${ }^{59}$

Not only did Rueff recommend purgation of the female body, he explicitly related these expulsive herbs to the promotion of fecundity. Similarly, in the seventeenth century Alessandro Massaria proposed the use of the remedy Hiera Piera, which purged excrements from the body, to restore obstructed menstruation. ${ }^{60} \mathrm{He}$ also listed several stronger purgative medicines which could be utilised should initial treatments prove unsuccessful. ${ }^{61}$ This, perhaps, suggests that stronger remedies were more likely to be viewed by both contemporary readers and historians as abortifacients but were not necessarily produced only for this operation; they could still be used for medicinal, beneficial, sexual health purposes.

These purging remedies which cleansed the womb of corrupt humours continued to be advocated across the period, into the eighteenth century. John Marten also acknowledged that strong purgative medicines could be required in the cure of this disorder. Notably the purge he recommended used a particularly powerful and dangerous aphrodisiac cantharides to excite the body. This example thus implies that these two types of substance shared common virtues, a conclusion which will be further explored below. In the

\footnotetext{
${ }^{59}$ Rueff 1637, p. 49.

${ }^{60}$ Massaria 1657, p. 21.

${ }^{61}$ Massaria 1657, pp. 24-5, 28-31.
} 
treatise, Marten wrote that to cure this disorder 'universal Remedies which evacuate upwards or downwards, must be first given' after which he listed several purging medicines. ${ }^{62}$ He followed this with the caution that:

'some Cases have been so inveterate, as that for the better forcing and opening of these obstructed Passages, we have been forc'd to have recourse to Cantharides, both inwardly and outwardly apply'd; for such a Distemper, unless in time remov'd utterly spoils Procreation, and much impedes Copulation. ${ }^{63}$

Here the remedy is designed solely with the promotion of generative health in mind. Although cantharides could conceivably have been used to purge a fetus from the body, Marten does not invoke the familiar warnings offered to pregnant women across the period by medical writers discussing potentially abortifacient substances. Although his recommendation could carry the implicit connotation of being abortive, his purges were explicitly understood and described solely within the framework of curing barrenness.

Purges designed to stimulate the monthly courses and restore the fertility of the womb were also discussed and recorded by female manuscript writers. These domestic collections move beyond the realms of medical theory to indicate medical practice. Receipt books descended from the medieval books of secrets which included medical, alchemical and trade recipes. ${ }^{64}$ The practice of keeping these books was 'profoundly influenced by the humanist reading and writing practices of the Renaissance ... which emphasized the

\footnotetext{
${ }^{62}$ Marten 1709, p. 109.

63 Ibid.

${ }^{64}$ Field in Dowd and Eckerle (eds) 2007, p.50.
} 
importance of collecting, organizing, and generating specialized knowledge in commonplace books structured thematically by topic. ${ }^{65}$ Receipt books were also experimental in nature; it was assumed that women would produce these remedies, using their own knowledge, refining them until they were satisfied with the overall efficacy of the remedy. ${ }^{66}$ Many remedies were also listed with comments upon their use such as probatum est (it is proven), or notes about particular cases in which they had worked. Although these texts do not give much detail, in terms of strength or quantity of ingredients, they effectively demonstrate the practical use and understanding of purges and other sexual health medications.

As with the published examples examined above it is clear that these could have been adopted for a more sinister use. It is also likely, because they were recorded in domestic receipt books, that they could have been accessed without the necessity of visiting a doctor or apothecary. Hence, they could have been used to remove a pregnancy without threatening the lady's virtue. However, to view them exclusively within this context is to undermine the importance of generative health and fertility to early modern women. Several examples highlight the link between provoking the terms and encouraging conception. One of the most descriptive was recorded by Lady Ayscough in her 1692 manuscript. The documented recipe was supposed 'To cleanse the Reines', thereby conforming to the stereotypical abortifacient virtues - the removal of obstructions or impurities in the womb. ${ }^{67}$ It contained parsley as its

\footnotetext{
${ }^{65}$ Field in Dowd and Eckerle (eds) 2007, p.51.

${ }^{66}$ Field in Dowd and Eckerle (eds) 2007, pp. 56-7.

${ }^{67}$ Wellcome Library (hereafter WL), MS1026, M.S.1026, Lady Asycough: Receipts of Physcik and Chirurgery, p. 104.
} 
primary ingredient, which was known to provoke the terms. Consequently it can be assumed that this was one of its aims. ${ }^{68}$ Nevertheless, the title given to this remedy also indicates that purging was not viewed as a detrimental or damaging course of action; it was cleansing and as such would leave the womb in a purer, more fertile state. The recipe was very complex, preventing it from being a suitable quick fix for an unwanted pregnancy. Moreover, in addition to the parsley it contained numerous provokers of lust, a trend that will be examined more thoroughly in due course, including arch angel flowers, hazel nuts, and the 'pythe' of an oxe back; this suggests that it was indeed supposed to cleanse and then invigorate the womb bringing it to a more pleasurable and fertile state. ${ }^{69}$ Lady Ayscough's final statement about the remedy further emphasises its place as a part of sexual health practice. She wrote that the remedy was 'Prob[atum est]: by Mrs Hone who being 4 years without issue being married conceived with Child upon ye taking thereof. ${ }^{70}$ Another similar example was recorded in the receipt book of the Boyle family. One family member recorded 'A Course of Physick much tried and approved to purge the womb of superfluous humours and to promote Conception in Barren Women'. This included many herbs noted for their ability to provoke the terms including pennyroyal, madder, calamint and savin. Yet it is once again clear that provoking the terms was thought to be beneficial to the

\footnotetext{
${ }^{68}$ Ibid. Information on the virtues of parsley from Culpeper 1653, p. 201.

${ }^{69}$ WL, M.S.1026, p.104. The Oxford English Dictionary Online suggests that 'pythe' referred to the spongy interior of organs or the substance occupying the spinal cord. In this case it may have been that the substance from the spinal cord was utilised, in keeping with the common medical theory that semen was produced in the brain and travelled to the testicles through the spinal column. This would suggest that the doctrine of signatures was employed here to pass on the potency of the ox to the woman consuming the decoction. The Oxford English Dictionary Online, www.dictionary.oed.com, accessed on 09/09/09.

${ }^{70}$ WL, M.S.1026, p.104.
} 
generative faculty of the womb. ${ }^{71}$ Thus, it would seem from the evidence presented in both printed medical works and manuscript collections, that provoking the terms was viewed as a form of cleansing purge which purified the womb and made it apt for conception.

The way in which these recipes were recorded leaves them open to interpretation. It was rare for women to include specific directions for creating remedies in these works, particularly the quantities of herbs needed. Thus, it has been plausible for historians to interpret the compounds as being heavily dominated by the expulsive faculties of the emmenagogue ingredients. Nevertheless, as Elaine Hobby has shown, the quantities of herbs used in recipes were left to the discretion of the woman making the recipe. ${ }^{72}$ Catherine Field has also explained that these documents were highly experiential. Women were expected to understand the quantities needed through a working system of testing; arriving at their own conclusions through trial and error. ${ }^{73}$ By utilising these remedies in their own practice it was expected that most women would have an intimate knowledge of the plants required and the amounts in which they were effective. As a result there was no need to record these trivial details. This means that from a historiographical perspective both interpretations are equally valid. Women at the time would have been able to interpret these recipes in the way that suited

\footnotetext{
${ }^{71}$ WL, M.S. 1340 , Boyle Family Collection of 712 receipts with some cookery receipts, fol. $35^{\vee}$. Another example is recorded in the book of Mary Doggett whose plaster for the back 'being laid to ye belly of a woman it causeth her Terms and makes her apt to conceive.' Again the provoking of menstruation was portrayed as the first step towards promoting the conception of a child. London British Library, M.S. Additional 27466, Mary Doggett Book of Receipts, 1684 , fol. $39^{v}$

${ }^{72}$ Hobby 1988, p. 167.

${ }^{73}$ Field in Dowd and Eckerle (eds) 2007, pp. 56-7.
} 
their circumstances; those needing an abortion could do so by including a more potent amount of emmenagogues. However, those seeking to cleanse and purge the womb to make it apt for conception could do so by balancing out the strength of potential abortifacients with the stimulating properties of provokers of venery.

\section{Emmenagogues and Aphrodisiacs}

It is clear that many medical writers and practitioners linked potential abortifacients and emmenagogues with the treatment of barrenness. In addition to this, it is also apparent that many purgative substances shared the same humoral virtues as potent heating aphrodisiacs, discussed previously. The humoral composition, according to the 1655 edition of the Pharmacopoeia Londinensis, of many emmenagogues classified them as hot and dry, usually to the second or third degree. Culpeper described hot in the second degree as 'something hotter than the Natural temper of Man', while those of the third degree were 'more powerful in their operations'. ${ }^{74}$ Plants classified in this way that could bring on the terms included: capper roots, catline thistle, flower-de-luce, dittany, fennel, cassia lignea, angelica and mugwort. $^{75}$ The parallel classification of these plants and heating sexual provocatives possibly reflects the similar nature of the causes of these two disorders. Both were predominantly attributed to excessive coldness and moisture in the body. It may also reflect the fact that these two disorders were

\footnotetext{
${ }_{75}^{74}$ Culpeper 1655, p. 346.

75 Culpeper 1655, pp. 3, 5, 7, 8, 14, 18, 19. Other examples can also be found on the following pages: maudlin, p. 17, water calamint, p. 21, ground pine, wild chamomile and germander, p. 23, sampier, p. 24, clary, p.28, common hore-hound, p. 30, thyme, p. 37.
} 
seen as commonly linked: suppressed menstruation caused barrenness, thus they should be treated with similar herbs. The number of herbs listed with these virtues in the text also suggests that this was not an uncharacteristic or exceptional occurrence. Culpeper's text was intended to reach a wider audience than the original dispensatory of the Royal College of Physicians, from which it was translated. Hence it is reasonable to assume that a relatively broad cross section of medical readers and practitioners who consumed this printed work would have considered these two types of plant as inherently similar.

Furthermore, numerous plants and medicaments were described as able to provoke lust as well as menstruation. At the beginning of the period Anthony Askham's 1550 herbal informed its readers that both mugwort (motherwort) and frankincense cleansed the womb and helped conception. ${ }^{76}$ Little is known about Askham's medical practices. His published almanacs, works on astrology and on herbal lore provide the only evidence of his work; as such the extent to which this knowledge was ever applied is uncertain. ${ }^{77}$ Yet, this again highlights the way in which these purgatives were not necessarily viewed as a means to destroy conceptions. In the seventeenth century, many more examples of herbs with this duality of virtues can be identified. John Gerard wrote in the Generall Historie of Plantes that saffron stirred up fleshly lust and brought down the flowers. ${ }^{78}$ Similarly he noted that stone cresses

\footnotetext{
${ }^{76}$ Askham 1550, Sig. Fiiir ${ }^{\mathrm{F}} \mathrm{Fvi}^{\mathrm{v}}$.

77 Information on Anthony Askham from The Oxford Dictionary of National Biography, www.oxforddnb.com/, accessed 26.11.09.

${ }^{78}$ Gerard 1633, pp. 151-4.
} 
'bringeth downe the floures ... and provoketh bodily lust'. ${ }^{79}$ This was supported in Arabella Aitkin's Family Magazine, a text supposed to influence domestic practice; where cresses were described as 'very warm, provoke to venery $\ldots$ and promote the menstrual flux' ${ }^{80}$ Similarly in later works, John Pechey wrote that common garden clary and mustard provoked the courses and stimulated venery. ${ }^{81}$ The simple recitation of the effects of these plants upon the generative body suggests that to authors and readers of the early modern period these two functions were not necessarily contradictory. This is perhaps further asserted by the fact that medical and herbal writers could provide cautions about the effects of some plants. John Pechey, unlike in his notes on clary and mustard, explicitly warned his readers that the common male fern was 'injurious to Women, and occasions Barrenness, hinders Conception, and causes Abortion. ${ }^{82}$ Similarly he wrote of Agarick that because it provoked the courses women with child should not consume it. ${ }^{83}$ It is clear therefore that in cases where a plant was emphatically abortifacient and potentially dangerous medical writers would caution their readers about its use. John Riddle in his work on contraception and abortion constructed a list of early modern emmenagogues which, given the evidence provided in this article, could also be categorised as provokers of venery including parsley, saffron and white pepper. ${ }^{84}$ Although this duality might appear contradictory, Totelin has identified that the dual use of plants was common: she argues that a fruit with sexual connotations was always relevant, no

\footnotetext{
${ }^{79}$ Gerard 1633, p. 251. Several other seventeenth century examples can be found in the Culpeper 1655, eringoes, p. 6, valerian pp. 2 and 10, carrot seeds, p. 42, chich peas, p.43.

${ }^{80}$ Atkyns 1741 , p. 8.

${ }^{81}$ Pechey 1707, pp. 54-5, 165.

${ }^{82}$ Pechey 1707, p.89.

${ }^{83}$ Pechey 1707, p. 198.

${ }^{84}$ Riddle 1992, p. 85.
} 
matter the complaint ${ }^{85}$ Consequently it may be conjectured that these plants could be used for entirely separate purposes. These herbs may have been employed solely to empty the womb without the associated ideas of enhancing procreation. Nonetheless, the examples seen here imply that these disorders were not only linked on a theoretical level, but on a practical one as well, giving greater credence to the idea that emmenagogues should be considered by historians as a treatment for barrenness, not just as abortifacients.

Although many emmenagogues could also be identified as provokers of lust, certain herbs were notoriously described as abortifacients during this period, particularly pennyroyal, savin and ergot, although others, including hellebore, chervil and bistort were also commonly listed. ${ }^{86}$ Descriptions of these plants, as noted with the common male fern above, were often accompanied by warnings that they should not be given to pregnant women. William Salmon wrote of savin that 'They open and cleanse the Womb so powerfully, that they are not be taken by Women with Child, lest they cause Abortion or Miscarriage'. ${ }^{87}$ Nevertheless, evidence can be identified which implies that even when these herbs were employed it may have been to induce fertility, rather than abortion or miscarriage. Compound remedies which were thought to promote the terms often contained numerous herbs of varying qualities and could include provokers of lust. It is plausible that these sexual stimulants were included simultaneously to stimulate menstruation or to insure that the

\footnotetext{
85 Totelin 2007, accessed through science direct.

${ }^{86}$ Mclaren 1984, p. 104.

${ }^{87}$ Salmon 1710, p. 1012
} 
rectified state of the womb, which now experienced regular monthly purgation, was fertile.

The most striking remedies which combine emmenagogues and sexual stimulants can be found in the Pharmacopoeia Londinensis. In this work Culpeper listed a compound water that was 'profitable for women in labour, that it provokes the terms. ${ }^{, 88}$ This water when viewed as a recipe seems to contain a half and half split of aphrodisiacs and abortifacients, the directions for its production stated:

Take of Cinnamon, Ginger, Galanga, Cloves, Nutmegs, Grains of Paradise, Seeds of Annis, Fennel, Caraway, of each one dram; Herbs of time, Mother of Time, Mints, Sage, Penyroyal, Pellitory of the wal, Rosemary, flowers of red Roses, Chamomel, Origanum, Lavender, of each one handful; infuse them twelve hours in twelve pints of Gascoign wine. ${ }^{89}$

Although, as has been established, some of the provokers of lust included in this remedy also stimulated menstruation, several more were included which did not. Moreover, the aphrodisiac substances were clustered together perhaps suggesting that this was the way in which they were expected to work. Thus, although this recipe would potentially have violently provoked the terms, under the humoral model in which many of these substances raised

\footnotetext{
${ }^{88}$ Culpeper 1655, p. 100.

$89 \mathrm{lbid}$. Original text is italicised.
} 
heat and desire, it would also have stimulated the fertility and pleasure of the womb inducing it to conceive a child.

Another electuary that served to open the womb and restore menstruation contained more provocatives than emmenagogues. Culpeper wrote of this remedy that it not only provoked the terms but strengthened the stomach and aided the distribution of nourishment around the body, effects that would have aided the womb in its ability to bear children. ${ }^{90}$ The remedy contained 'Cinnamon fifteen drams; cassia Lignea, Alicampane roots, of each half an ou[n]ce: Glanga, seven drams; Cloves, long Pepper, both sorts of cardamoms, Ginger, mace, Nutmegs, Wood of Aloes, of each three drams: Saffron one dram: Sugar five drams: Musk two scruples'. ${ }^{91}$ The prominence of sexual stimulants in these recipes strengthens the suggestion that many of these potentially abortive substances would, indeed, have had a beneficial effect on the generative system, hence it is plausible that they were considered to contain a dual virtue. Similarly, some substances which were promoted without a list of ingredients were also thought to work in this twofold manner. The 'English PILLS FOR THE SCURVY' described in an anonymous text on Some Particular Rebellious Distempers were advocated for their ability to 'Cure Barrenness effectually, whether the fault be in the Man or Woman; they exalting the Generative Faculty, cleansing and strengthening the Spermatick Vessels, resisting all Foulness and Infection in the Act of

\footnotetext{
${ }^{90}$ Culpeper 1655, p. 236.

91 Ibid. Original text is italicised. The contemporary medical text De Morbis Fœminis also listed a strong purging remedy that contained several stimulating substances including, sperage, fennel, cinnamon, parsley, fennel seed, yellow rape seed, caraway, galinga and saffron. Massaria 1657, p. 28.
} 
Generation; bring down the Terms in Women and Maids'. ${ }^{92}$ Once more the emphasis here is placed upon the ability of the medicine to promote the generative faculty and enliven the reproductive organs: provoking menstruation was a part of this process, not a separate action. From these examples it would seem that remedies were not always presented in medical literature as a covert way of designating abortions, but rather held a legitimate place in medical treatments for infertility.

\section{Conclusions}

Felix Platter noted in 1662 that 'gentle Purges corrected with hot Spices, whether they work or not, do vehemently provoke Venery'. ${ }^{93}$ It is apparent that for many medical writers of the early modern period purging the womb was not necessarily a damaging or negative action; it could stimulate venery and promote fertility. This article has demonstrated that in line with the suggestions of Van de Walle and Totelin early modern emmenagogues should be considered as substances which served a twofold, and perhaps sometimes contradictory, purpose. Although it is clear that women could and did use these remedies to remove an untimely or unwanted pregnancy, this was not their primary function. The overwhelming necessity of the fertile body to experience menstruation meant that emmenagogues could easily be understood as an essential component of sexual health practices designed to increase the fertility of the body. Moreover, the close association between purges and heating sexual provocatives suggests that many of these

\footnotetext{
${ }^{92}$ Anon. 1670, pp. 1, 12.

${ }^{93}$ Platter 1662, p.171.
} 
substances were indeed recommended for their ability to stimulate and invigorate the generative organs. Finally, it has also been shown that these similarities and associations existed in medical texts associated with both medical theory and medical practice. Consequently it is plausible to assume that both the medical elites and a variety of medical readers and practitioners understood, recommended and used menstrual provocatives to further the fertility of the body, rather than to provoke an abortion. Therefore, this article surmises that suggestions about the extent of abortion practices in early modern England need to be tempered by the consideration of the medical and social concern with fertility. Considering the history of emmenagogues in this way will provide a more holistic understanding of the abortion, fertility and other sexual health practices in early modern England.

\section{Acknowledgements}

I would like to thank Sarah Toulalan and Alexandra Walsham for all of their support, advice and guidance during the writing of my thesis and this article.

\section{Bibliography}

\section{Primary sources}

British Library, London.

Wellcome Library, London.

Anon. 1670, An Account of the Causes of Some Particular Rebellious

Distempers..., London.

Anon. 1739, The Ladies Physical Directory..., London: by the author's appointment, at the gentlewoman's at the Two Blue Posts in Haydon-Yard in the Minories. 
Askham A. 1550, A Lytel Herball of the Properties of Herbes Newly Amended, London: Wyllyam

Powell, Fletestrete at the signe of the George nexte to Saynte Dunstones Churche.

Astruc J. 1743, A Treatise on all the Diseases Incident to Women, London: T. Cooper at the Globe in Pater-Noster-Row.

Atkyns A. 1741, The Family Magazine: In Two Parts, London: J. Osborn, at the Golden-Ball in Paternoster-Row.

Ball J. 1770, The Female Physician: Or, Every Woman Her Own Doctress, London: L. Davis, near Gray's-Inn-Gate, Holborn.

Barrough P. 1590, The Method of Phisick, London: Richard Field, dwelling in the Blacke-friers by Lud-gate.

Bracken H. 1737, The Midwives Companion: Or, A Treatise of Midwifery Wherein the Whole Art is Explained, London: Clarke at the Golden Ball in Duck-Lane near West-Smithfield; and J. Shuckburgh, at the Sun near the Inner-Temple-Gate in Fleet-Street.

BuchanW. 1772, Domestic Medicine or the Family Physician, Philadelphia: John Dunlap for R. Aitken, [at his] book-store, nearly opposite the London Coffee-Hou[se] in Front-Street.

Culpeper N. 1653, The English Physician and Family Dispensatory, London: Wordsworth Editions.

Culpeper N. 1655, Pharmacopoeia Londinensis: Or the London Dispensatory, London: Peter Cole in Leaden-Hall, and at the sign of the Printing-Press in Cornhil, neer the Royal Exchange. 
Freind J. 1729, Emmenologia..., London: T. Cox at the Lamb under the Royal-Exchange, Cornhill.

Gerard J. 1633, The Herball or Generall Historie of Plantes, London: Adam Islip loice Norton and Richard Whitakers.

Lemnius L. 1658, The Secret Miracles of Nature, London: Jo. Streater, and are to be sold by Humphrey Moseley...John Sweeting...John Clark...and George Sawbridge.

Marten J. 1709, Gonosologium Novum: Or, A New System of all the Secret Infirmities and Diseases, Natural, Accidental and Venereal in Men and Women..., London: N. Crouch in the Poultry,

S. Crouch, in Cornhil, J. Knapton, and M. Atkins in St Paul's Church-Yard, A. Collins at the Black Boy in Fleet-Street P. Varenne at Seneca's Head in the Strand, C. King, Westminster-Hall.

Massaria A. 1657, De Morbis Foemineis: The Womans Councellor..., London: John Streater.

Pechey J. 1707, The Compleat Herbal of Physical Plants, London: R. and J. Bonwicke, at the Red Lion in St Paul's Church-Yard.

Platter F. 1662, A Golden Practice of Physick..., London: Peter Cole, printer and book-seller, at the sign of the Printing-press in Cornhill, near the Royal Exchange.

Rueff J. 1637, The Expert Midwife, Or An Excellent and Most Necessary Treatise of the Generation and Birth of Man, London: E. G[riffin] for S. B[urton]. Originally Published in 1554. 
Salmon W. 1710, Botanalogia. The English Herbal...Volume II, London:

Printed by I. Dawks, for $\mathrm{H}$. Rhodes, at the Star, the corner of Bride-Lane, in

Fleet-Street; and J. Taylor, at the Ship in Pater-noster-Row.

Sharp J. 1671, The Midwives Book Or the Whole Art of Midwifery Discovered, London: Simon Miller, at the Star at the West End of St Pauls.

\section{Secondary sources}

Bullough V. L. 1973, 'An Early American Sex Manual, or, Aristotle Who?',

Early American Literature, 7, 236-46.

Cadden J. 1993, The Meaning of Sex Difference in the Middle Ages:

Medicine, Science and Culture, Cambridge: Cambridge University Press.

Crawford P. 2004, Blood, Bodies and Families in Early Modern England, Harlow: Pearson.

Dobranski S. 2005, Readers and Authorship in Early Modern England, Cambridge: Cambridge University Press.

Field C. 2007, "'Many hands hands": Writing the Self in Early Modern Women's Recipe Books', in Dowd M. M. and Eckerle J. A. (eds), Genre and Women's Life Writing in Early Modern England, Aldershot: Ashgate, 49-65.

Fissell M. 2004, Vernacular Bodies: The Politics of Reproduction in Early Modern England, Oxford: Oxford University Press.

Furdell E. L. 2002, Publishing and Medicine in Early Modern England, London: University of Rochester Press.

Galley C. 1994, 'A Never-ending Succession of Epidemics? Mortality in EarlyModern York', Social History of Medicine, 7, 29-57.

Ganev R. 2007, 'Milkmaids, Ploughmen, and Sex in Eighteenth-Century Britain', Journal of the History of Sexuality, 16, 40-67. 
Gowing L. 1997, 'Secret Births and Infanticide in Seventeenth-Century

England', Past and Present, 156, 87-115.

Gowing L. 2003, Common Bodies: Women, Touch and Power in

Seventeenth-Century England, New Haven and London: Yale University

Press.

Harkness D. 2006, 'Nosce Teipsum: Curiosity, the Humoural Body and the

Culture of Therapeutics in Late Sixteenth- and Early Seventeenth-Century

England', in Evans R. J. W. and Marr A. (eds), Curiosity and Wonder from the Renaissance to the Enlightenment, Aldershot: Ashgate, 171-92.

Hitchcock T. 1997, English Sexualities: 1700-1800, Basingstoke: Macmillan.

Hobby E. 1988, Virtue of Necessity; English Women's Writing 1649-1688, London: Virago.

King H. 2004, Disease of Virgins: Green Sickness, Cholorsis and the Problems of Puberty, London: Routledge.

Klepp S. E. 2001, 'Colds, Worms, and Hysteria: Menstrual Regulation in Eighteenth-Century America', in Van de Walle E. and Renne E. (eds), Regulating Menstruation, Chicago and London: Chicago University Press, 2238.

Leong E. 2008, 'Making Medicines in the Early Modern Household', Bulletin of the History of Medicine, 82, 145-68.

McClive C. 2005, 'Menstrual Knowledge and Medical Practice in Early Modern France, c. 1555-1761', in Shail A. and Howie G. (eds), Menstruation: A Cultural History, Basingstoke: Palgrave Macmillan, 76-89.

Mclaren A. 1981, "'Barrenness against Nature”: Recourse to Abortion in PreIndustrial England', Journal of Sex Research, 17, 224-37. 
Mclaren A. 1984, Reproductive Rituals: The Perception of Fertility in England from the Sixteenth Century to the Nineteenth Century, London, New York:

Methuen.

Mendleson S. and Crawford P. 1998, Women in Early Modern England 15501720, Oxford: Clarendon Press.

Porter R. 1989, Health for Sale: Quackery in England 1660-1859,

Manchester: Manchester University Press.

Porter R. and Hall L. 1995, The Facts of Life: The Creation of Sexual

Knowledge in Britain, 1650-1950, New Haven and London: Yale University

Press.

Razzell P. and Spence C. 2007, 'The History of Infant, Child and Adult

Mortality in London, 1550-1850', The London Journal, 32, 271-92.

Riddle J. M. 1991, 'Oral Contraceptives and Early-Term Abortifacients during

Classical Antiquity and the Middle Ages', Past and Present, 132, 3-32.

Riddle J. M. 1992, Contraception and Abortion from the Ancient World to the Renaissance, Cambridge, MA: Harvard University Press.

Shorter E. 1984, A History of Women's Bodies, Harmondsworth: Penguin.

Stone L. 1990 [1970], The Family, Sex and Marriage in England 1500-1800, London: Penguin.

Thorndike L. 1941, A History of Magic and Experimental Science, Part Four, The Sixteenth Century, New York and London: Columbia University Press. Totelin L. 2007, 'Sex and Vegetables in the Hippocratic Gynaecological Treatises', Studies in History and Philosophy of Science, Part C: Studies in History and Philosophy of Biological and Biomedical Sciences, 38, 531-40. 
Totelin L. 2009, Hippocratic Recipes: Oral and Written Transmission of Pharmacological Knowledge in Fifth- and Fourth-Century Greece, Leiden and Boston: Brill.

Toulalan S. 2007, Imaging Sex Pornography and Bodies in Seventeenth-

Century England, Oxford: Oxford University Press.

Van de Walle E. 1997, 'Flowers and Fruits: Two Thousand Years of Menstrual Regulation', Journal of Interdisciplinary History, 28, 183-203.

Van deWalle E. and Renne E. 2001, Regulating Menstruation, Chicago and London: Chicago University Press.

Wallis P. 2006, 'Apothecaries and the Consumption and Retailing of Medicines in Early Modern London', in Hill Curth L. (ed.), From Physick to Pharmacology: Five Hundred Years of British Drug Retailing, Aldershot: Ashgate, 13-27. 